\title{
M410, a combretastatin A4 analogue, disrupts microtubules and inhibits HIF-1 $\alpha$ in human breast cancer cells
}

\author{
HANG YANG $^{1 *}$, QING XIA ${ }^{2 *}$, YONG ZOU $^{3}$, KEFENG WANG $^{1}$, WENQI JIANG ${ }^{1}$ and YUCHEN CAI $^{1}$ \\ ${ }^{1}$ State Key Laboratory of Oncology in South China, Collaborative Innovation Center for Cancer Medicine, \\ Sun Yat-sen University Cancer Center, Guangzhou, Guangdong 510060; ${ }^{2}$ Department of Oncology, Shanghai Jiaotong \\ University Affiliated First People's Hospital, Shanghai 201620; ${ }^{3}$ School of Pharmaceutical Sciences, \\ Sun Yat-sen University, Guangzhou, Guangdong 510006, P.R. China
}

Received February 27, 2015; Accepted April 20, 2015

DOI: $10.3892 /$ or.2015.3975

\begin{abstract}
Hypoxia-inducible factor-1 (HIF-1) is a primary transcriptional factor that targets a series of genes participating in angiogenesis and cell proliferation. HIF-1 is a heterodimer consisting of a constitutively-expressed HIF-1 $\beta$ subunit and an oxygen-regulated HIF-1 $\alpha$ subunit. Overexpression of HIF-1 $\alpha$ has been found in various types of cancer. Targeting HIF-1 $\alpha$ may be a novel approach to cancer therapy. Previous findings showed that a newly synthesized compound (Z)-3,4',5trimethoxylstilbene-3'-O-phosphate disodium (M410), an analogue of the microtubule-targeting agent, combretastatin A4, inhibited the polymerization of bovine brain tubulin and induced mitotic arrest. The aim of the present study was to determine the mechanism of M410 destabilizes microtubules and inhibits HIF-1 $\alpha$ in breast cancer cells. We performed 3-(4,5-dimethylthiazol-2-yl)-2,5-diphenyltetrazolium bromide (MTT) assay, immunofluorescence and confocal microscopy, ELISA assay, transient transfections and reporter gene assay, immunoblot analysis and isolation and analysis of RNA to evaluate the mechanisms of M410 on breast cancer. SPSS 17.0 was used to analyze the data. The results showed that the growth of breast cancer cells was inhibited in a dose-dependent manner. MDA-MB-231 was the most sensitive, with a 50\% growth inhibition $\left(\mathrm{GI}_{50}\right)$ of $111.4 \pm 2.2 \mathrm{nM}$. HIF-1 $\alpha$ expression was clearly reduced following M410 treatment in a dose-dependent manner. M410 downregulated the nuclear accumulation of HIF- $1 \alpha$, and the strong correlation between disruption of the microtubule cytoskeleton and the inhibition of HIF-1 $\alpha$ expression was independent of mitotic arrest. Furthermore,
\end{abstract}

Correspondence to: Professor Wenqi Jiang or Dr Yuchen Cai, State Key Laboratory of Oncology in South China, Collaborative Innovation Center for Cancer Medicine, Sun Yat-sen University Cancer Center, Guangzhou, Guangdong 510060, P.R. China

E-mail: jiangwenqi2009@126.com

E-mail: caiyuchen@126.com

${ }^{*}$ Contributed equally

Key words: breast carcinoma, HIF-1 $\alpha$, M410, microtubule
M410 inhibited HIF-1 $\alpha$ at the post-transcriptional level and inhibited the vascular endothelial growth factor (VEGF) at the transcription level. M410 downregulated HIF-1 $\alpha$ expression in a proteasome-independent manner. In conclusion, M410 depolymerized microtubules and downregulated HIF-1 $\alpha$ protein levels in a proteasome-independent manner and reduced the mRNA of HIF-1-targeted genes in the MDA-MB-231 breast cancer cell line.

\section{Introduction}

Breast cancer (BC) is a global health problem and one of the principal causes of female morbidity and mortality $(1,2)$. It is a major public health concern in both developed and developing countries (3). Approximately $10-17 \%$ of breast cancers are defined as triple-negative (TN), i.e, the absence of estrogen and progesterone receptor, and of overexpression and/or amplification of the HER-2 (4,5). Although advances have made in clinical and experimental oncology studies, the prognosis of $\mathrm{TN}$ breast cancer remains extremely poor (6). The clinical impact of molecular-targeted therapy in the TNBC population remains unclear (7). Mounting evidence of the signal transduction pathways for transcription factors suggests that these pathways could offer crucial targets for cancer therapy.

The transcription factor hypoxia-inducible factor-1 (HIF-1) is a heterodimeric protein composed of an oxygen-regulated HIF-1 $\alpha$ and a constitutively-expressed HIF-1 $\beta$ subunit. Under normoxic conditions, HIF-1 $\alpha$ is hydroxylated on proline residue 402 and/or 564, which is required for binding of the von Hippel-Lindau protein, the recognition subunit of an E3 ubiquitin ligase that targets HIF-1 $\alpha$ for proteasomal degradation (8). However, hydroxylation decreases under hypoxic conditions, enabling HIF-1 $\alpha$ to accumulate and dimerize with HIF-1 $\beta$. The functional transcription factor then binds at the core hypoxia response element, 5'-RCGTG-3', to induce genes involved in angiogenesis, glycolysis, de-differentiation, invasion and metastasis. Overexpression of HIF-1 $\alpha$ is associated with increased mortality in many cancer types (9-11).

Numerous cancer chemotherapeutic agents target angiogenesis in tumors to reduce primary tumor growth. Response to anti-vascular endothelial growth factor (VEGF) therapy has, however, been poor, as intratumoral hypoxia arising from 
impaired angiogenesis causes HIF-1-dependent metastasis and expansion of cancer stem cell pools (12). HIF-1 $\alpha$ is the main transcription factor mediating the hypoxic response, which promotes the transcription of angiogenic factors, such as VEGF and leads to increased glycolysis via the inhibition of mitochondrial oxidative phosphorylation (13). The critical role of the hypoxia response network and HIF-1 $\alpha$ has resulted in it being viewed as an ideal target for small molecule intervention. Small molecule inhibitors of HIF- $1 \alpha$ are widely studied and are considered important due to their central role in tumorigenesis.

Combretastatins are natural cis-stilbenes that are isolated from the bark of the African willow tree Combretum caffrum. Combretastatin A4 is the most prominent representative of this group of compounds, which exerts high anti-mitotic and anti-angiogenic activities (14). Previous studies (15) showed that a new CA4 analogue, (Z)-3,4',5-trimethoxylstilbene-3'-Ophosphate disodium (M410) was a potent inhibitor of bovine brain tubulin polymerization in vitro. In experiments on nude mice in vivo, M410 inhibited the growth of human colon carcinoma xenografts and reduced microvessel density in tumor tissues. M410 exhibited a prominent cytotoxic effect, which downregulated HIF-1 $\alpha$ expression, reduced nuclear HIF-1 $\alpha$ and subsequently downregulated VEGF mRNA. In the present study, we assessed the activity of M410 on TNBC cell lines and confirmed the mechanism of the inhibitory effects of M410 on a MDA-MB-231 breast cancer cell line.

\section{Materials and methods}

Cell lines and culture conditions. The Human BT549, MDA-MB-453, MDA-MB-231 and SK-BR-3 BC cell lines were maintained in Dulbecco's modified Eagle's medium (DMEM; Invitrogen) supplemented with $10 \%$ fetal bovine serum (FBS; Hyclone, Logan, UT, USA), $100 \mathrm{U} / \mathrm{ml}$ penicillin and $100 \mu \mathrm{g} / \mathrm{ml}$ streptomycin. The cells were cultured in a humidified atmosphere containing $5 \% \mathrm{CO}_{2}$ at $37^{\circ} \mathrm{C}$. For the treatment of hypoxia, the cells were incubated in an MIC-101 chamber (Billups Rothenberg, Inc., Del Mar, CA, USA) containing $5 \% \mathrm{CO}_{2}$ balanced with $\mathrm{N}_{2}\left(<0.1 \% \mathrm{O}_{2}\right)$ or exposed to $\mathrm{CoCl}_{2}(200 \mu \mathrm{M})$ for 4-6 h.

Reagents and antibodies. M410 was synthesized by the Guangzhou Institute of Chemistry, Chinese Academy of Sciences (15). M410 was dissolved in distilled water to yield a 10-mM stock solution. Cycloheximide (CHX) was dissolved in distilled water to yield a 10-mg/ml stock. MG132 (C2211) and monastrol (M8515) (both from Sigma-Aldrich, St. Louis, MO, USA) were respectively dissolved in DMSO as stocks of $10 \mathrm{mM}$. The primary antibodies used were: HIF-1 $\alpha$ antibody (610959) and HIF-1 $\beta$ antibody (611078) (both from BD Transduction Laboratories, Bedford, MA, USA), $\beta$-tubulin antibody (no. 2128; Cell Signaling Technology, Danvers, MA, USA), monoclonal anti- $\beta$-tubulin antibody (D00057; Sigma-Aldrich), $\beta$-actin antibody (no. 3700; Cell Signaling Technology), NF- $\kappa$ B-p65 antibody (SAB, no. 21012) and c-Fos antibody (SAB, no. 21667).

3-(4,5-Dimethylthiazol-2-yl)-2,5-diphenyltetrazolium bromide (MTT) assay. Cells were plated in a 96-well plate and cultured in medium with various concentrations of M410 added after
24 h. After 68-h incubation, MTT was added to each well (100 $\mu \mathrm{g} /$ well) and incubated for an additional $4 \mathrm{~h}$. The insoluble formazan produced was dissolved with $200 \mu \mathrm{l}$ DMSO, and optical density was measured using an ELISA reader (Thermo Labsystems, Espoo, Finland) at wavelengths of 570 and $630 \mathrm{~nm}$. Experiments were performed in triplicate. From these results, the percentages of live cells in each well were estimated and plotted against the drug concentrations as dose-response curves, from which the $50 \%$ growth inhibition $\left(\mathrm{GI}_{50}\right)$ was derived.

Immunofluorescence and confocal microscopy. Exponentially growing cells were placed on $15-\mathrm{mm}$ coverslips in 6-well plates and the cells were allowed to attach overnight. The following day, the cells were treated with the indicated agents for $24 \mathrm{~h}$ and subjected to hypoxia or remained normoxic for an additional $6 \mathrm{~h}$. The cells were fixed with pre-warmed $4 \%$ paraformaldehyde (PFA) at $37^{\circ} \mathrm{C}$ for $30 \mathrm{~min}$ and washed with PBS for four times. After being permeabilized with PBS containing $0.5 \%$ Triton $\mathrm{X}-100$ ( $\mathrm{vol} / \mathrm{vol}$ ) for $15 \mathrm{~min}$ at room temperature and washed with PBS, the cells were blocked with $5 \%$ bovine serum albumin (BSA) for $1 \mathrm{~h}$ and then incubated with primary antibody at $4^{\circ} \mathrm{C}$ overnight. Subsequently, the cells were washed with PBS and re-incubated with DyLight ${ }^{\mathrm{TM}} 549$ or 488-labeled antibody in a dark room for $1 \mathrm{~h}$. The cells were then stained for the nuclei with $0.1 \mu \mathrm{g} / \mathrm{ml}$ DAPI in a dark room for $10 \mathrm{~min}$. The coverlips were fixed on the slides using an antifade reagent (Life Technologies, Carlsbad, CA, USA) and then observed using an Olympus FV100 confocal microscope.

ELISA for VEGF. VEGF concentrations in media from treated and untreated cells were determined using a quantitative sandwich enzyme immunoassay (Human VEGF Quantikine ELISA kit; R\&D Systems, Inc., Minneapolis, MN, USA) according to the manufacturer's instructions. The results were expressed as a concentration of VEGF (pg/ml) per total protein amount from each well.

Immunoblot analysis. Lysates were prepared from $4 \times 10^{5}$ cells by dissolving cell pellets in $100 \mu \mathrm{l}$ of lysis buffer (20 $\mathrm{mM} \mathrm{Na}_{2} \mathrm{PO}_{4}$, pH 7.4, $150 \mathrm{mM} \mathrm{NaCl}, 1 \%$ Triton X-100, $1 \%$ aprotinin, $1 \mathrm{mM}$ phenymethysulfonyl fluoride, $10 \mathrm{mg} /$ ml leupeptin, $100 \mathrm{mM} \mathrm{NaF}$ and $2 \mathrm{mM} \mathrm{Na}_{3} \mathrm{VO}_{4}$ ). The lysates were centrifuged at $14,000 \mathrm{rpm}$ for $20 \mathrm{~min}$. The supernatant was collected. Protein concentrations were determined using a BCA protein assay kit (Thermo Scientific). The protein content was determined using the Bio-Rad protein assay. Protein $(10 \mu \mathrm{g})$ was loaded in each well of $10-12 \%$ SDS-PAGE gels. Resolved proteins were electrophoretically transferred to PVDF membranes and incubated sequentially with primary antibody and HRP-conjugated secondary antibody (Cell Signaling Technology). After washing, the bound antibody complex was detected using LumiGLO reagent (no. 7003; Cell Signaling Technology) and XAR film (XBT-1; Kodak, Rochester, NY, USA) according to the manufacturer's instructions.

Isolation and analysis of RNA. Total RNA was isolated from MDA-MB-231 cells treated and untreated with M410 using TRIzol reagent (Life Technologies). Then, $1 \mu \mathrm{g}$ of RNA was 
Table I. Primers used for RT-PCR.

\begin{tabular}{llllc}
\hline \multirow{2}{*}{ mRNA } & \multicolumn{1}{c}{ Forward primer } & \multicolumn{1}{c}{ Reverse primer } & $\begin{array}{c}\text { Product size } \\
(\mathrm{bp})\end{array}$ & $\begin{array}{c}\text { Annealing temperature } \\
\left({ }^{\circ} \mathrm{C}\right)\end{array}$ \\
\hline GLUT1 & GTGCCCATGTATGTGGGTGA & CTAGCGCGATGGTCATGAGT & 649 & 60 \\
HIF-1 $\alpha$ & CCCCAGATTCAGGATCAGACA & CCATCATGTTCATTTTCGC & 704 & 59 \\
VEGFA & TCACCAAGGCCAGCACATAG & GAGGCTCCAGGGCATTAGAC & 202 & 62 \\
$\beta$-actin & TCTACAATGAGCTGCGTGTG & GGTGAGGATCTTCATGAGGT & 314 & 56 \\
\hline
\end{tabular}

HIF-1 $\alpha$, hypoxia-inducible factor-1 $\alpha$; VEGFA, vascular endothelial growth factor A.

A
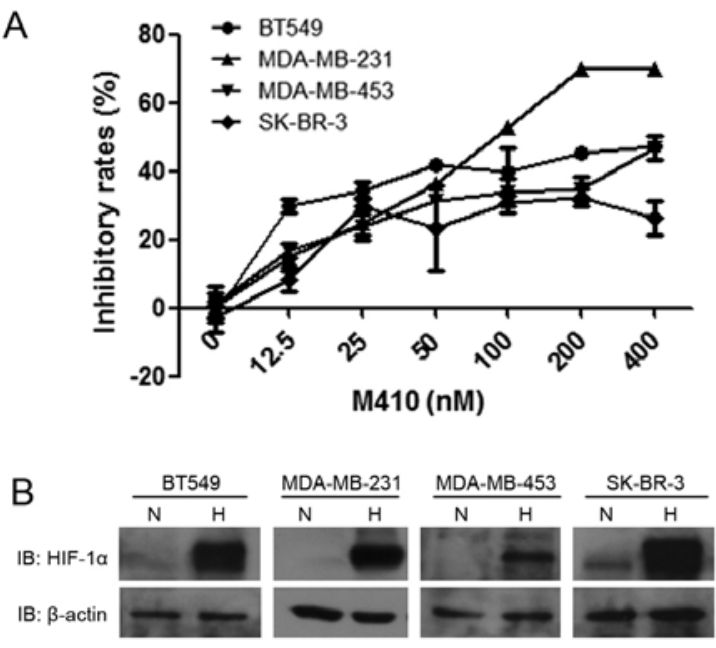

MDA-MB-231

C

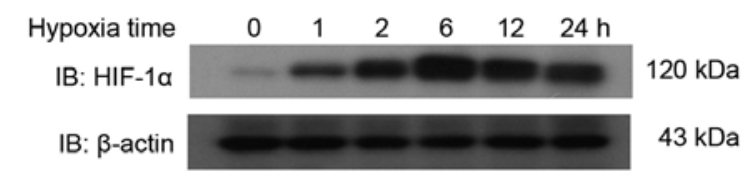

D

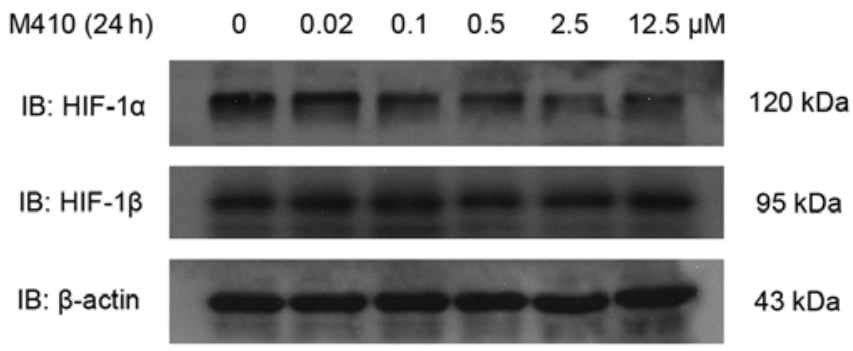

E

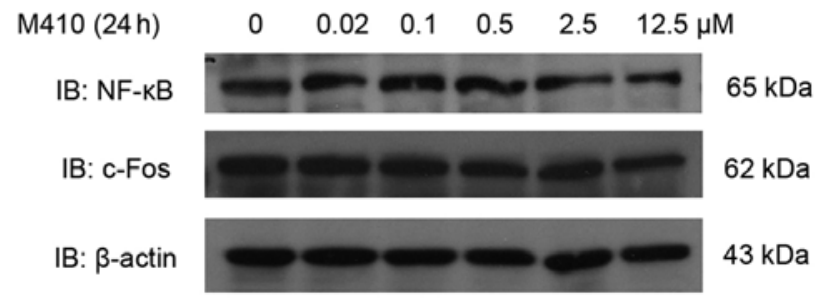

Figure 1. M410 treatment reduces the HIF-1 $\alpha$ protein level in MDA-MB-231 cells. (A) M410 inhibits the growth of four breast cancer cell lines in vitro. (B) The expression levels of HIF-1 $\alpha$ under normoxic and hypoxic conditions of the four breast cancer cell lines. (C) The expression levels of HIF-1 $\alpha$ during different exposure time to hypoxia in MDA-MB-231 cells. (D) MDA-MB-231 cells were treated with increasing concentrations of M410 for $24 \mathrm{~h}$ and then subjected to hypoxia for an additional $6 \mathrm{~h}$. (D) HIF-1 $\alpha$, HIF-1 $\beta$, and (E) NF- $\kappa$ B and c-Fos levels were tested by immunoblotting and $\beta$-actin was used by an inner control. HIF-1, hypoxia-inducible factor-1; M410, (Z)-3,4',5-trimethoxylstilbene-3'-O-phosphate disodium.

reverse transcribed in a $20-\mu 1$ reaction using a Transcriptor First Strand cDNA Synthesis kit (Roche Applied Science, Mannheim, Germany) according to the manufacturer's instructions. PCR was performed using PCR Master Mix (Promega, Madison, WI, USA) and $2 \mu 1$ of cDNA was used for each reaction. The PCR conditions were: denaturation for $2 \mathrm{~min}$ at $94^{\circ} \mathrm{C}, 35$ cycles of $94^{\circ} \mathrm{C}$ for $45 \mathrm{sec}$, annealing temperatures for $45 \mathrm{sec}$, and extension at $72^{\circ} \mathrm{C}$ for $60 \mathrm{sec}$. A 10 -min extension at $72^{\circ} \mathrm{C}$ was carried out to the end. PCR products were visualized with GelRed on $1.5 \%$ agarose gels. The primers were designed using the Primer-BLAST and shown in Table I.

Statistical analysis. Experiments were repeated three times. The results of multiple experiments are given as the mean $\pm \mathrm{SE}$. Statistical analysis was performed using the statistical software package SPSS 17.0. P-values were calculated using a one-way ANOVA test or the Student's t-test. $\mathrm{P}<0.05$ was considered to be statistically significant.

\section{Results}

M410 reduces $H I F-1 \alpha$ protein level in MDA-MB-231 cells. First, we examined the viability of the four BC cell lines by MTT assay in the presence of M410 with different concentrations (0-400 nM). MDA-MB-231 was the most sensitive, with the concentration of $\mathrm{GI}_{50}$ of $111.4 \pm 2.2 \mathrm{nM}$ at $72 \mathrm{~h}$. Western blot analyses showed that HIF-1 $\alpha$ was weakly expressed in the SK-BR-3 cells, but was not expressed in the remaining three BC cells under normoxia. Following treatment with hypoxia for $6 \mathrm{~h}$, the expression of HIF-1 $\alpha$ was highly induced in all the cell lines (Fig. 1B). Under the indicated time of hypoxia, the levels of HIF-1 $\alpha$ protein increased rapidly, peaked at the 6-h time-point, and was then reduced gradually (Fig. 1C). HIF-1 $\alpha$ expression was clearly reduced after M410 treatment in a dose-dependent manner. To examine whether these inhibitions were specific for HIF-1 $\alpha$, the regulated subunit of HIF-1, we also assessed the effect of M410 


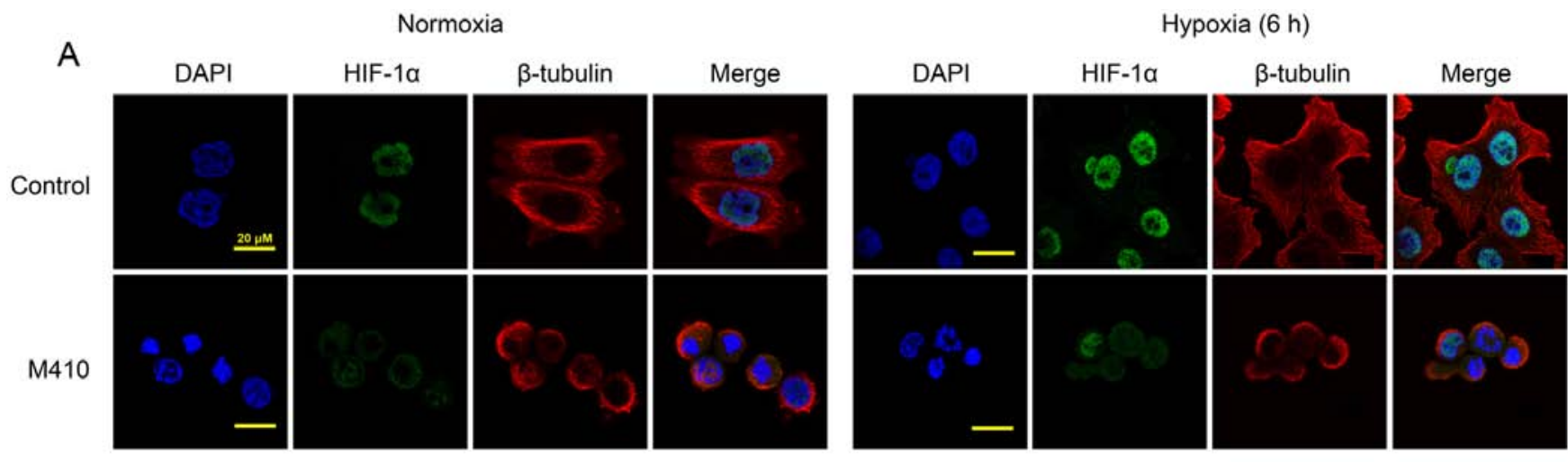

B

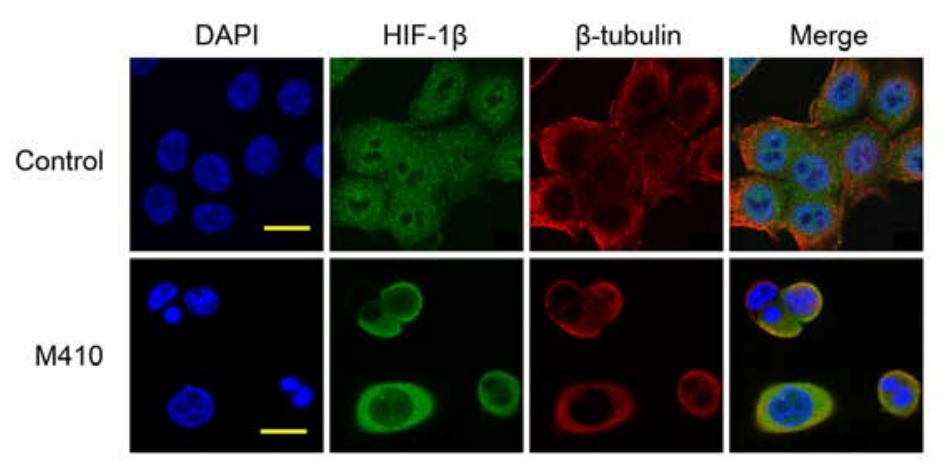

Hypoxia (6 h)

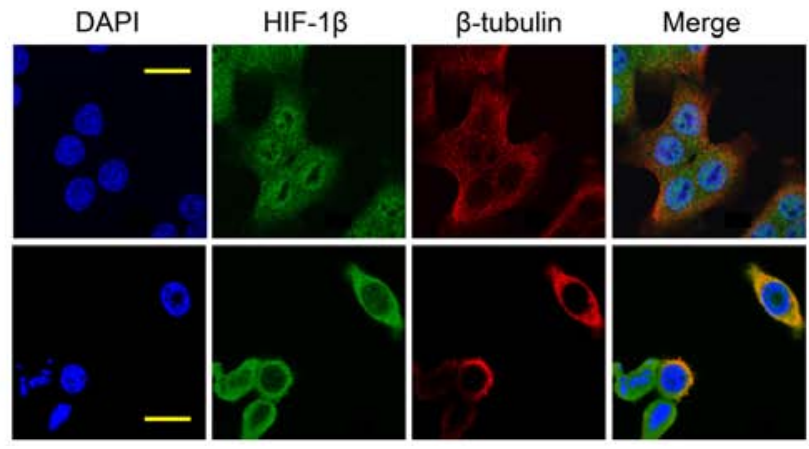

Figure 2. M410 depolymerizes microtubules and inhibits the nuclear accumulation of HIF-1 $\alpha$. (A) MDA-MB-231 cells were treated with $0.5 \mu$ M M410 for $24 \mathrm{~h}$ and then subjected to hypoxia, or remained in normoxia for an additional $6 \mathrm{~h}$. The cells were fixed and processed for double immunofluorescence with anti-HIF-1 $\alpha$ (green) and anti- $\beta$-tubulin (red) antibody. After stained with DAPI and fixed, the cells on coverlips were analysised by confocal laser scanning microscopy. (B) MDA-MB-231 cells were treated similarly and labeled with anti-HIF-1 $\beta$ (green) and anti- $\beta$-tubulin (red) antibody. HIF-1, hypoxia-inducible factor-1; M410, (Z)-3,4',5-trimethoxylstilbene-3'-O-phosphate disodium.

on HIF-1 $\beta$ expression. HIF-1 $\beta$ was not affected by M410 treatment. Similarly, transcription factors such as $\mathrm{NF}-\kappa \mathrm{B}$ and c-Fos were not affected (Fig. 1D and E).

M410 depolymerizes microtubules and inhibits the nuclear accumulation of HIF-1 $\alpha$. M410 has been shown to depolymerize microtubules in human vesicular endothelial cells (HUVECs) as well as in tumor cells resulting in $\mathrm{G}_{2} / \mathrm{M}$ arrest (15). We investigated the correlation between the effects of M410 on microtubules and its effects on HIF-1 $\alpha$ (Fig. 2). Using laser scanning confocal microscopy, MDA-MB231 cells treated with or without M410 were observed by double-labeled antibodies against $\beta$-tubulin and HIF-1 $\alpha$. In untreated control cells, we observed an intricate and intact microtubule network while we observed the depolymerization of microtubules in the M410-treated cells. No significant changes in the microtubule network were observed in the control cells after hypoxia. Under the normoxic conditions, HIF-1 $\alpha$ was barely detectable while it predominantly accumulated in the nucleus after exposure to hypoxia. Nuclear localization of HIF-1 $\alpha$ was confirmed by staining with DAPI. The treatment of M410 significantly reduced the hypoxiainduced nuclear accumulation of HIF-1 $\alpha$. Consistent with the results of western blotting, the treatment of M410 had no effect on the expression of HIF-1 $\beta$ (Fig. 2B). In the untreated cells, HIF-1 $\beta$ was localized in the nucleus and the cytoplasm, especially in the nucleus. Under hypoxic conditions, HIF-1 $\beta$ did not accumulate in the nucleus. The treatment of M410 affected the subcellular localization of HIF-1 $\beta$.

M410 inhibition of HIF-1 $\alpha$ function is independent of mitotic arrest. Since M410 has been shown to induce mitotic arrest (15), we clarified the correlation between the inhibition of HIF-1 $\alpha$ and the mitotic arrest. Subsequently, we treated MDA-MB-231 cells with monastrol, which is not a microtubule-targeting compound and is known to induce mitotic arrest by inhibiting the mitotic kinesin Eg5, utilizing M410 as a positive control. As shown in Fig. 3A, monastrol had no effect on HIF-1 $\alpha$ protein levels even at concentrations that induced a significant mitotic arrest. Although arrested in the interphase, the microtubule network and the spindles (arrow) were intact in the monastrol-treated cells compared with the depolymerization of microtubule in the M410-treated cells. These results suggested that the inhibition of HIF-1 $\alpha$ function by M410 was independent of M410-induced mitotic arrest (Fig. 3B).

M410 inhibits HIF-1 $\alpha$ transcriptional activity. To determine the effects of M410 treatment on HIF-1 transcriptional activity, we examined the VEGF protein level in the supernatant medium from M410-treated MDA-MB-231 cells. Consistently with the reduced levels of HIF-1 $\alpha$ protein levels by M410, VEGF protein levels were also significantly decreased in a dose-dependent manner under hypoxia (Fig. 4A). To determine whether the downregulation of HIF-1 $\alpha$ by M410 occurred 
A

\begin{tabular}{cc}
$M 410(24 h)$ \\
\hline 0 & $0.5 \quad 2.5 \mu M$
\end{tabular}

$\frac{\text { Monastrol }(24 \mathrm{~h})}{0 \quad 10 \quad 100 \mu \mathrm{M}}$

IB: HIF-1a
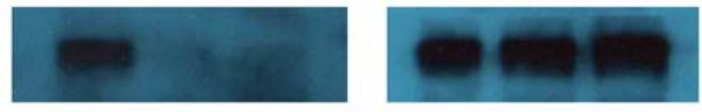

$120 \mathrm{kDa}$

IB: $\beta$-actin
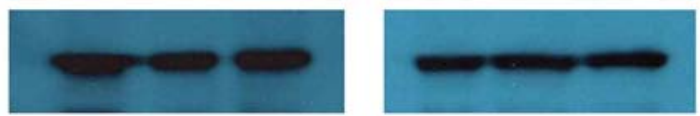

\section{$43 \mathrm{kDa}$}

B $\quad M 410(\mu \mathrm{M})$
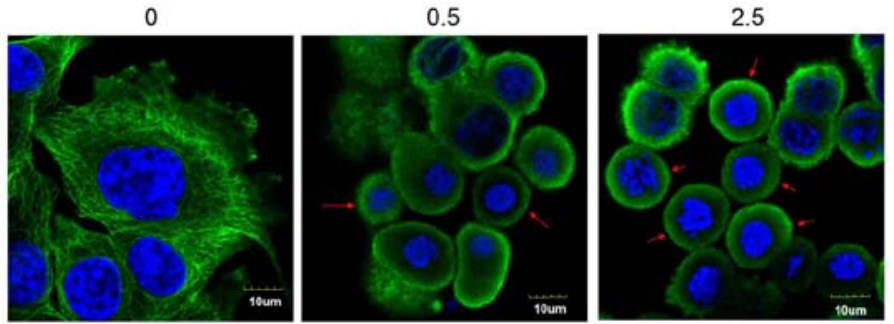

Monastrol $(\mu \mathrm{M})$

0

10

100
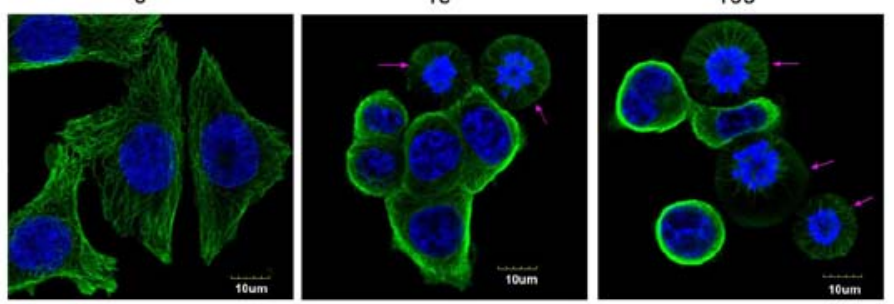

Figure 3. M410 inhibition of HIF-1 $\alpha$ function is independent of mitotic arrest. (A) MDA-MB-231 cells were treated with indicated concentrations of M410 or monastrol for $24 \mathrm{~h}$ and then subjected to hypoxia for an additional $6 \mathrm{~h}$. The cells were lysed and processed for western blotting. Equal amounts of protein were loaded, transferred and immunoblotted with anti-HIF-1 $\alpha$ and anti- $\beta$-actin antibody. (B) After the same treatment as above, the cells were fixed and labeled with anti- $\beta$-tubulin (green) antibody and DAPI (blue). Staining was analyzed by confocal laser scanning microscopy. Red arrows show the depolymerization of microtubules and mitotic arrest cells induced by M410. Purple arrows show the mitotic cells with spindles induced by monastrol. HIF-1, hypoxia-inducible factor-1; M410, (Z)-3,4',5-trimethoxylstilbene-3'-O-phosphate disodium.

A
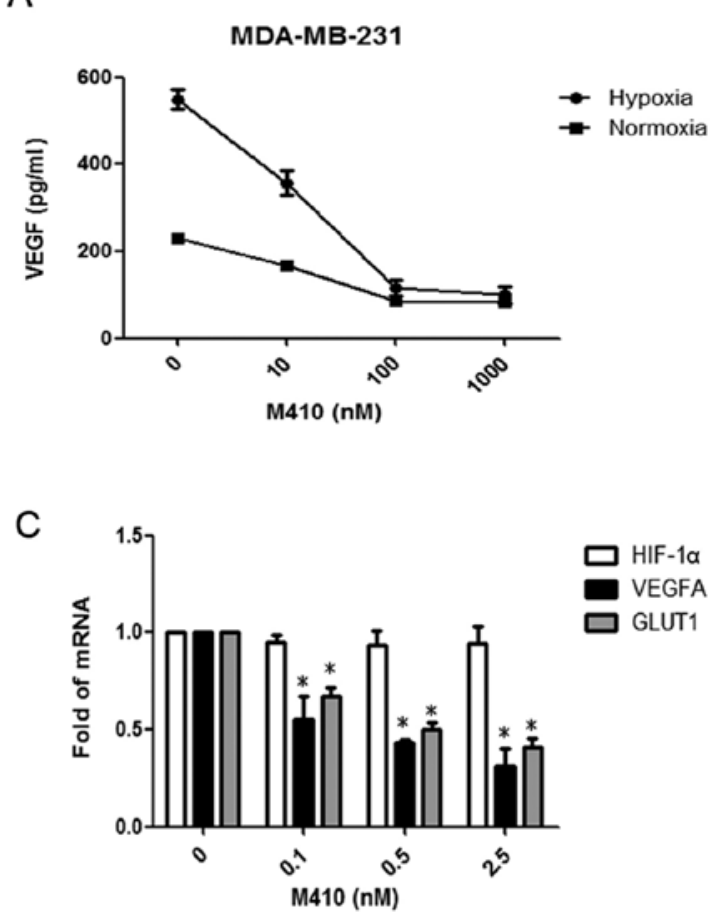

B

\begin{tabular}{|c|c|}
\hline & M4 \\
\hline 0 & 0.1 \\
\hline
\end{tabular}

HIF-1 $1 \alpha$

VEGFA

GLUT1

$\beta$-actin

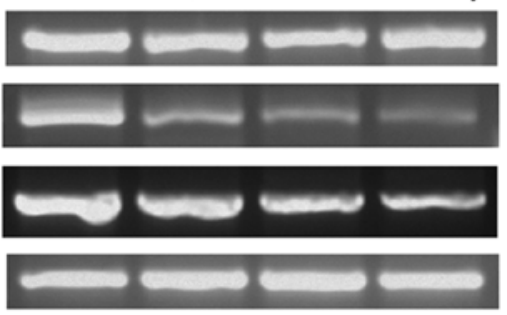

Figure 4. M410 inhibits HIF-1 $\alpha$ transcriptional activity. (A) The supernatant media from cultured MDA-MB-231 cells treated with M410 were analyzed for VEGF expressed as $\mathrm{pg} / \mathrm{ml}$ per total amount of protein in each well. (B) Total RNA was prepared from M410-treated MDA-MB-231 cells subjected to hypoxia. Two-step RT-PCR was performed and mRNA levels were determined by densitometry using $\beta$-actin as an inner control. (C) The quantification of mRNA levels by densitometry following normalization to $\beta$-actin. mRNA levels from untreated cells are given the value of $100 \%$ ("P<0.05). HIF-1, hypoxia-inducible factor-1; M410, (Z)-3,4',5-trimethoxylstilbene-3'-O-phosphate disodium; VEGF, vascular endothelial growth factor. 
A

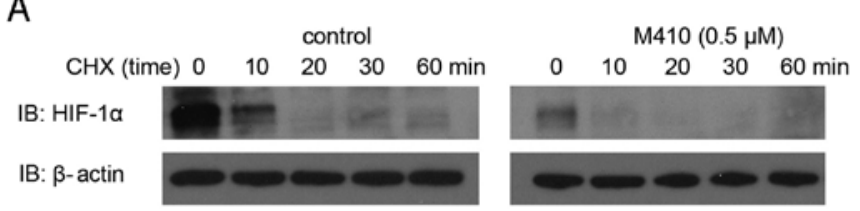

B

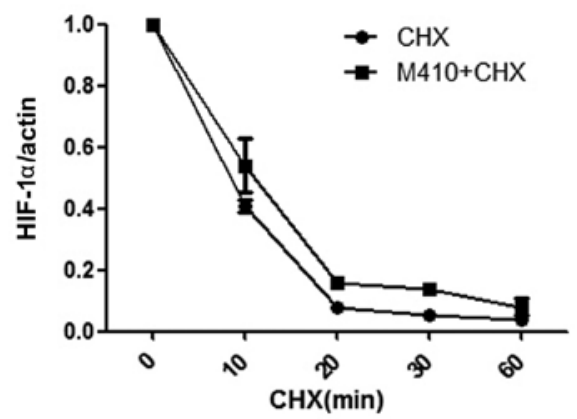

C

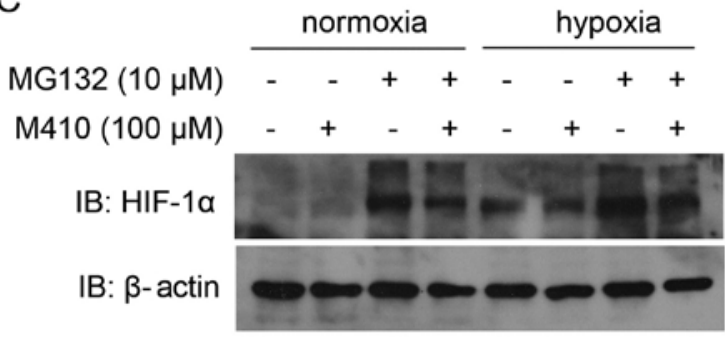

Figure 5. M410 downregulates HIF-1 $\alpha$ expression in a proteasome-independent manner. (A) MDA-MB-231 cells were treated with the indicated concentrations of M410 for $24 \mathrm{~h}$ and then subjected to hypoxia for an additional $6 \mathrm{~h}$. Cycloheximide (CHX) was added at a final concentration of $10 \mu \mathrm{g} / \mathrm{ml}$ for the indicated time points. Equal amounts of protein were loaded, transferred and immunoblotted with anti-HIF- $1 \alpha$ and anti- $\beta$-actin antibody. (B) Quantification of HIF-1 $\alpha$ levels by densitometry following normalization to $\beta$-actin. HIF-1 $\alpha$ levels from the control and M410-treated cells are given the value of $100 \%$. (C) MDA-MB-231 cells were treated with $100 \mu \mathrm{M}$ M410 in the presence or absence of $10 \mu \mathrm{M} \mathrm{MG132}$ for $4 \mathrm{~h}$ Equal amounts of protein were loaded, transferred and immunoblotted with anti-HIF-1 $\alpha$ and anti- $\beta$-actin antibody. HIF-1, hypoxia-inducible factor-1; M410, (Z)-3,4',5-trimethoxylstilbene-3'-O-phosphate disodium.

at the transcriptional level, we extracted total RNA from M410-treated MDA-MB-231 cells and performed two-step RT-PCR. HIF-1 $\alpha$ mRNA levels were not significantly changed by M410 (Fig. 4B and C). On the other hand, the mRNA levels of VEGF and another HIF-1 target gene, i.e., GLUT1 glucose transporter were significantly decreased by M410 treatment.

M410 downregulates HIF- $1 \alpha$ expression in a proteasomeindependent manner. To examine the effect of M410 on the HIF-1 post-transcriptional process, we examined the M410 treatment on HIF- $1 \alpha$ protein stability by using the protein translation inhibitor CHX. As CHX inhibits new protein synthesis, the HIF-1 $\alpha$ level would mostly reflect the degradation process of HIF- $1 \alpha$ protein. Untreated or M410-treated cells were exposed to CHX from 0 to $60 \mathrm{~min}$ and HIF- $1 \alpha$ levels were analyzed by western blotting (Fig. 5A). We assessed whether M410 combined with CHX treatment affected the half-life of HIF- $1 \alpha$ compared with CHX treatment alone. The results indicated no statistical significance (Fig. 5B). To eliminate the possibility that M410 affects HIF-1 $\alpha$ ubiquitina- tion and degradation via the proteasome pathway, we treated MDA-MB-231 cells with the MG132 proteasome inhibitor. In the untreated cells, MG132 led to enhanced HIF-1 $\alpha$ protein levels while in the M410-treated cells, MG132 did not restore the inhibition of M410 on HIF-1 $\alpha$ protein levels under hypoxia or normoxia (Fig. 5C).

\section{Discussion}

Hypoxia is a feature of most tumors that often arises due to rapid cell division, aberrant tumor angiogenesis and blood flow. Persistent hypoxia leads to a selection of genotypes favoring survival and promoting tumor angiogenesis, epithelial-to-mesenchymal transition, invasiveness and metastasis, as well as suppression of immune reactivity $(16,17)$. HIFs are optimally characterized markers mediating cell responses to hypoxic stress. Of the HIF family members, HIF-1 $\alpha$ is the most well characterized (18). Increased HIF- $1 \alpha$ levels are associated with increased risk of mortality in many human cancer types, including those of the breast, brain, colon, bladder, esophageal, head/neck/oropharynx, liver, pancreatic, lung, gastric, and uterus, skin, as well as in acute lymphocytic and myeloid leukemias (19). It was shown that HIF-1 $\alpha$ was overexpressed in BRCA-1 germline mutation-related breast cancer (20) and associated independently with shortened survival in patients with lymph node-negative breast carcinoma and in patients with lymph node-positive ones $(21,22)$. HIF-1 $\alpha$ has been a prime target for anticancer therapies (23). PX-478 is the first inhibitor of HIF-1 $\alpha$, which decreased the HIF-1 $\alpha$ protein expression and had potent antitumor activity (24). Kong et al (25) reported that echinomycin inhibited HIF-1 DNA binding to endogenous promoters and resulted in cell apoptosis. Kim et al (26) found that a potent angiogenesis inhibitor G0811, targeted HIF-1 $\alpha$ signal transduction and suppressed HIF- $1 \alpha$ stability in cancer cells and inhibited in vitro and in vivo angiogenesis. In addition, G0811 effectively decreased the expression of VEGF, which is one of the target genes of HIF-1 $\alpha$. In a previous study (15), six synthesized stilbene derivatives were screened for their cytotoxic activity against human tumor cells and of these compound M410 exhibited a most prominent cytotoxic effect. M410 has been shown to compete with colchicine for tubulin binding and to disrupt microtubules leading to mitotic arrest in colon cancer cell lines. However, the exact mechanism whereby M410 destabilizes microtubules and inhibits HIF-1 $\alpha$, as well as the relationship between the two remains unclear.

In the present study, we first investigated the antitumor effect of M410 in BC cell lines in a concentration-dependent manner. We then confirmed that M410 depolymerizes microtubules and inhibits the nuclear accumulation of HIF-1 $\alpha$ expression in a proteasome-independent manner in hypoxia. The effect was specific as other transcription factors such as HIF-1 $\beta$, NF- $\mathrm{kB}$ and c-Fos, were not affected. Since M410 has been shown to induce mitotic arrest, we clarified the relationship between the inhibition of HIF-1 $\alpha$ and mitotic arrest. We used the non-microtubule-targeting agent, monastrol, to exclude the possibility that the inhibition of M410 on HIF-1 $1 \alpha$ is the consequence of mitotic arrest. The results suggest that the strong correlation between disruption of the microtubule cytoskeleton and inhibition of HIF-1 $\alpha$ function is independent of mitotic arrest. We also assessed the role of microtubule-targeting 
agents, such as Vincristine (VCR) and Taxol, on the HIF-1 $\alpha$ protein levels in breast cancer cells (data not shown). VCR and Taxol had similar effects on HIF-1 $\alpha$ as M410, suggesting a strong correlation between the disruption of microtubules and inhibition of HIF-1 $\alpha$. However, the mechanisms regarding how the stability of microtubules affects the translation of HIF-1 $\alpha$ levels remain to be determined. Furthermore, we examined whether the downregulation of HIF-1 $\alpha$ by M410 occurred at the transcriptional or translational level or other sides by extracting total RNA from MDA-MB-231 cells and found HIF-1 $\alpha$ mRNA levels were not significantly changed by M410. Thus, we concluded that M410 inhibited HIF-1 $\alpha$ at the translation level. VEGF is the most potent angiogenic growth factor in solid tumors. It also has a range of other functions, including induction of vascular permeability and supporting survival of endothelial cells. We showed that the mRNA level of VEGF was significantly decreased by M410 treatment, which was consistent with findings of a previous study (25). Our results identified that HIF-1 target gene, GLUT1 glucose transporter was also significantly decreased by M410 treatment. However, future in vivo investigation is required to confirm these results.

In conclusion, our results have shown that M410 depolymerizes microtubules and downregulates HIF-1 $\alpha$ protein levels in a proteasome-independent manner and reduces the mRNA of HIF-1-targeted genes in the MDA-MB-231 breast cancer cell line. Notably, we suggest a strong correlation between the inhibition of HIF-1 $\alpha$ and the disruption of microtubules in breast cancer cells.

\section{Acknowledgements}

This study was supported by grants as follows: Young Scientist Project of the National Natural Science Foundation of China (no. 81201716), Core Technology Program for Strategy Emerging Industries of Guangdong Province (no. 2011A081401002) and the Science and Technology Program of Guangzhou City (no. 2014J4100224).

\section{References}

1. Althuis MD, Dozier JM, Anderson WF, Devesa SS and Brinton LA: Global trends in breast cancer incidence and mortality 1973-1997. Int J Epidemiol 34: 405-412, 2005.

2. Jemal A, Bray F, Center MM, Ferlay J, Ward E and Forman D: Global cancer statistics. CA Cancer J Clin 61: 69-90, 2011.

3. Forbes JF: The incidence of breast cancer: the global burden, public health considerations. Semin Oncol 24 (Suppl 1): S1-20-S1-35, 1997.

4. Rakha EA, El-Sayed ME, Green AR, Lee AH, Robertson JF and Ellis IO: Prognostic markers in triple-negative breast cancer. Cancer 109: 25-32, 2007.

5. Dent R, Trudeau M, Pritchard KI, Hanna WM, Kahn HK, Sawka CA, Lickley LA, Rawlinson E, Sun P and Narod SA: Triple-negative breast cancer: clinical features and patterns of recurrence. Clin Cancer Res 13: 4429-4434, 2007.

6. Foulkes WD, Smith IE and Reis-Filho JS: Triple-negative breast cancer. N Engl J Med 363: 1938-1948, 2010.

7. Hudis CA and Gianni L: Triple-negative breast cancer: an unmet medical need. Oncologist 16 (Suppl 1): 1-11, 2011.
8. Kaelin WG Jr and Ratcliffe PJ: Oxygen sensing by metazoans: the central role of the HIF hydroxylase pathway. Mol Cell 30: 393-402, 2008.

9. Zhong H, De Marzo AM, Laughner E, Lim M, Hilton DA, Zagzag D, Buechler P, Isaacs WB, Semenza GL and Simons JW: Overexpression of hypoxia-inducible factor 1alpha in common human cancers and their metastases. Cancer Res 59: 5830-5835, 1999.

10. Sun HC, Qiu ZJ, Liu J, Sun J, Jiang T, Huang KJ, Yao M and Huang C: Expression of hypoxia-inducible factor- $1 \alpha$ and associated proteins in pancreatic ductal adenocarcinoma and their impact on prognosis. Int J Oncol 30: 1359-1367, 2007.

11. Rasheed S, Harris AL, Tekkis PP, Turley H, Silver A, McDonald PJ, Talbot IC, Glynne-Jones R, Northover JM and Guenther T: Hypoxia-inducible factor-1alpha and -2alpha are expressed in most rectal cancers but only hypoxia-inducible factor-1alpha is associated with prognosis. Br J Cancer 100: 1666-1673, 2009.

12. Conley SJ, Gheordunescu E, Kakarala P, Newman B, Korkaya H, Heath AN, Clouthier SG and Wicha MS: Antiangiogenic agents increase breast cancer stem cells via the generation of tumor hypoxia. Proc Natl Acad Sci USA 109: 2784-2789, 2012.

13. Papandreou I, Cairns RA, Fontana L, Lim AL and Denko NC: HIF-1 mediates adaptation to hypoxia by actively downregulating mitochondrial oxygen consumption. Cell Metab 3: 187-197, 2006.

14. Mikstacka R, Stefański T and Różański J: Tubulin-interactive stilbene derivatives as anticancer agents. Cell Mol Biol Lett 18: 368-397, 2013.

15. Cai YC, Zou Y, Ye YL, Sun HY, Su QG, Wang ZX, Zeng ZL and Xian LJ: Anti-tumor activity and mechanisms of a novel vascular disrupting agent, (Z)-3,4',5-trimethoxylstilbene-3'-O-phosphate disodium (M410). Invest New Drugs 29: 300-311, 2011.

16. Wilson WR and Hay MP: Targeting hypoxia in cancer therapy. Nat Rev Cancer 11: 393-410, 2011.

17. Vaupel P, Mayer A and Höckel M: Tumor hypoxia and malignant progression. Methods Enzymol 381: 335-354, 2004.

18. Gong L, Zhang W, Zhou J, Lu J, Xiong H, Shi X and Chen J: Prognostic value of HIFs expression in head and neck cancer: a systematic review. PLoS One 8: e75094, 2013.

19. Semenza GL: Defining the role of hypoxia-inducible factor 1 in cancer biology and therapeutics. Oncogene 29: 625-634, 2010.

20. van der Groep P, Bouter A, Menko FH, van der Wall E and van Diest PJ: High frequency of HIF-1alpha overexpression in BRCA1 related breast cancer. Breast Cancer Res Treat 111: 475-480, 2008

21. Bos R, van der Groep P, Greijer AE, Shvarts A, Meijer S, Pinedo HM, Semenza GL, van Diest PJ and van der Wall E: Levels of hypoxia-inducible factor- $1 \alpha$ independently predict prognosis in patients with lymph node negative breast carcinoma. Cancer 97: 1573-1581, 2003.

22. Schindl M, Schoppmann SF, Samonigg H, Hausmaninger $H$, Kwasny W, Gnant M, Jakesz R, Kubista E, Birner P and Oberhuber G; Austrian Breast and Colorectal Cancer Study Group: Overexpression of hypoxia-inducible factor $1 \alpha$ is associated with an unfavorable prognosis in lymph node-positive breast cancer. Clin Cancer Res 8: 1831-1837, 2002.

23. Semenza GL: Targeting HIF-1 for cancer therapy. Nat Rev Cancer 3: 721-732, 2003.

24. Welsh S, Williams R, Kirkpatrick L, Paine-Murrieta G and Powis G: Antitumor activity and pharmacodynamic properties of PX-478, an inhibitor of hypoxia-inducible factor-1alpha. Mol Cancer Ther 3: 233-244, 2004.

25. Kong D, Park EJ, Stephen AG, Calvani M, Cardellina JH, Monks A, Fisher RJ, Shoemaker RH and Melillo G: Echinomycin, a small-molecule inhibitor of hypoxia-inducible factor-1 DNA-binding activity. Cancer Res 65: 9047-9055, 2005.

26. Kim KH, Jung HJ and Kwon HJ: A new anti-angiogenic small molecule, G0811, inhibits angiogenesis via targeting hypoxia inducible factor (HIF)-1 $\alpha$ signal transduction. Biochem Biophys Res Commun 441: 399-404, 2013. 